\title{
Logical-argumentative Basics of Educational Culture
}

\author{
Vitaly Ivlev \\ National Research University \\ Bauman Moscow State Technical University \\ Moscow, Russia \\ vitalijivlev@yandex.ru
}

\author{
Yury Ivlev \\ Department of Logic \\ Moscow State University \\ Moscow, Russia \\ ivlev.logic@yandex.ru
}

\author{
Marina Ivleva \\ Department of Social Philosophy \\ Peoples' Friendship University of Russia \\ Moscow, Russia \\ marinanonna@yandex.ru
}

\begin{abstract}
The logical-argumentative culture is a part of educational culture. It includes ideological part - the knowledge of types of knowledge expressions, their meaning and significance, methods of reasoning, methods of justification of knowledge etc., as well as the logicalargumentative methodology (technologies of development of justified knowledge, methods of explanation of expressions and justification of statements etc.). The third part of the logicalargumentative culture includes the skills of application of the logical and argumentative methodology in research of academic disciplines, in communication and in the process of practical activities.
\end{abstract}

Keywords-educational culture; logical culture; argumentation; criticism; types of argumentation; rules of argumentation

\section{INTRODUCTION}

In addition to the moral culture and the culture of behavior, there is an educational culture. In this regard, an educated person is more cultured than an uneducated one. The educational culture is in the knowledge that a person gained in the process of education, as well as in the process of communication, reading literature etc. Among this knowledge there is knowledge about what is in the reality worldview. Worldview is a describing part of educational culture. Another part is prescriptive knowledge methodology. Methodology includes technologies of application of knowledge, for example, technologies of justification of statements, suggested by other people, technologies of development of management decisions [1] [2] [3] [4].

In order to master logical-argumentative culture, it is recommended to study the world viewing part of logic and teachings about argumentation (teaching about types of

This paper was financially supported by the Ministry of Education and Science of the Russian Federation on the program to improve the competitiveness of Peoples' Friendship University (RUDN University) among the world's leading research and education centers in the 2016-2020 (The Agreement number 02.A03.21.0008). expressions of language and their meanings and significance, methods of explanation and justification of knowledge, types of opinions etc.). In addition, it is necessary to develop skills of application of logical and argumentative methodology in study of academic disciplines, in communication and in the process of practical activities.

There is a notion that an ability of logical thinking and correct argumentation of knowledge is in human nature. This notion is incorrect. It's refuted by research conducted in our country in 30th of last century. In this research cottagers that lived in distant villages and almost led a subsistence economy, were asked questions. For example, a cottager was said, that according to government order, every district center shall have a post office. They said that this order was already executed. The cottager was asked if he agrees that every district center has post office. Usually, the cottager agreed.

Then he was said that such and such settlement is a district center. Cottager agreed with that and said that it is a district center of a district he's living in. Then the cottager was asked a question: "Does it follow from the statements "Every district center has a post office" and "Mentioned settlement is a district center" that "This settlement has a post office?". Cottager answered affirmatively and added "I was in district center many times and saw a post office there".

Then the cottager was asked again, does he agree that every district center has a post office. Cottager agreed. He also agreed that another mentioned settlement is a district center and added that it's a district center of a neighboring district. But at the question that does it follow from these two statements that that other settlement has a post office, the cottager answered negatively. He said "I do not know what I do not know. I've never been there".

Logical culture of a modern educated person is more developed than logical culture of the cottagers in question. We even find the misunderstanding of such simple judgments strange (they're called categorical syllogisms). 
But if the logical culture is not in the human's nature, how is it formed?

Logical culture of thinking is mastered during communication, study in school and university, in the process of reading literature. Constantly meeting with those or other ways of thinking, we're gradually adopting them and start to understand, which ones are correct and which ones are not. There is a fact that shows how in the process of education, even without studying logic, a person learns how to think logically. Chief Procurator of Holy Synod K. P. Pobedonostsev declared "The Russian population doesn't need education for it teaches how to think logically".

The specified path of formation of logical culture (without studying logic) can be called "spontaneous". It is not the best way since people that did not study logic, as a rule, do not possess such or others logical methods, and furthermore, possess different logical culture, which does not promote mutual understanding. It's confirmed by research in which students that did not study logic yet were given an assignment of analyzing a series of arguments. It was required to answer which arguments the student considered to be correct, which are incorrect, and which he had no definite opinion about. It was also suggested to say which methods, according to these correct arguments, he actively owns, that is if he himself reasons in that way, and which he does not actively own. The answers of the students about the same arguments were different.

In some way, the culture of argumentation is also formed spontaneously. However, it is also not the best way. Without learning the basics of argumentation, they are substituted with non-argumentative methods (psychological, rhetorical etc.). It's especially important for engineers to possess logical-argumentative culture since engineers are managers in most cases.

\section{ThE BASICS OF THE CULTURE OF ARGUMENTATION}

Let's characterize the argumentation.

Argumentation is a justification of some knowledge through other knowledge and methods of logic and methodology. Knowledge is not only that what can be expressed as judgments, but also as norms, evaluations, orders, decisions, problems, hypotheses, concepts etc. In everyday life, especially in politics, non-argumentative factors are used, which affect the acceptance of some or other knowledge as justified (psychological, rhetorical etc.). These factors can be compared to catalysts and inhibitors in chemistry 1 . Non-argumentative factors promote or hinder the argumentation, and sometimes substitute it.

Argumentation consists of four parts. First is knowledge (position) that is being justified. Second is knowledge (positions) by which the justification is performed. Third is logical methods (argumentation logic). Fourth is methodology.

\footnotetext{
${ }^{1}$ The former speed up the reaction and the latter slow it down. Still, both are called catalysts.
}

Knowledge that is being justified is called thesis argument.

Knowledge that is used in justification of thesis are called arguments, justifications, or reasons.

Logical structure of argumentation, or its logical relation between arguments and thesis, is called form of argumentation

Thesis is designated by the letter "T" and Methodology by the letter "M".

Arguments are designated as: A1, ..., An, where $n^{3} 1$. As arguments are judgments, norms, assessments etc. For the designation of argumentation is symbol $\sim>$.

Argumentation can be presented as such:

$\mathrm{M},\{\mathrm{A} 1, \ldots, \mathrm{An}\} \sim \mathrm{T}$.

The indication of methodology, as well as worldview in which there is argumentation, can be omitted. We will also omit the curly braces. In this case, argumentation can be presented as such: A1, .., An $\sim \mathrm{T}$.

Possible situations.

First. Set of arguments $\{A 1, \ldots, A n\}$ confirms thesis T. That is, argumentation has the form A1, .., An »> T. (»> confirmation relation.)

Second. Thesis logically follows specified arguments: $\mathrm{A} 1, \ldots$, An P T.

Third. There is no confirmation relation between arguments and thesis: A1, ..., An » T. (»- relation between arguments and thesis in logical form that is not consecution nor confirmation.). In latter case argumentation is considered incorrect or seeming.

By degree of justification of thesis, argumentation is divided into evident and non-evident.

Argumentation is evident if and only if arguments are fully justified knowledge and form is a reasoning that allows to extract fully justified knowledge from other fully justified knowledge. Such are deductive reasoning and some kinds of inductive reasoning (full induction, scientific induction based on the general, strict analogy).

If a reasoning is justified only with arguments that are judgments, then evident is an argumentation in which arguments are judgments, truth of which is established, and form is reasoning which allows for true conclusion with true premises.

Argumentation is non-evident when arguments, or at least some of them, are not reliable and are only plausible, or/and when the form is a reasoning that does not provide the true conclusion with true premises.

Critique. Critique is "destruction" of argumentation and/or establishment of falsity or low likelihood of a statement. In the latter case, that is when the falsity or low likelihood is established, critique is called counterargumentation, and criticized statement is called thesis (designated as T). In analogy with argumentation, in counter- 
argumentation it is natural to highlight arguments, or counter-arguments, and form (designated, respectively, A, ..., An and $\sim$ ), as well as methodology. A special case of counter-argumentation is a rebuttal.

Rebuttal is a justification of falsity of a knowledge using logical-methodological means and fully justified arguments

Refutable argumentation is argumentation in which arguments (at least, some of which) are not fully justified statements and/or form is a reasoning that does not provide true conclusion with true premises.

In the process of argumentation and critique there can be mistakes of two kinds: deliberate and unintentional. Deliberate mistakes are called a sophisms, and people who make these mistakes - sophists. Reasonings that contain deliberate mistakes are also called sophisms. The name "sophism" comes from Greek "sophisma" - "clever reasoning, artifice, deceit".

In ancient Greece there were people that, for a fee, were instructing the art of winning in an argument, no matter its subject, the art of turning a weak reasoning to strong, and turn strong, if it is opponent's reasoning, to weak. They also taught how to argue even on a subject you know nothing about. Protagoras was such a teacher. About him is the famous sophism of Euathlus.

Euathlus was taught the art of arguing by Protagoras. As by agreement between a teacher and a student, Euathlus had to pay for his education after first trial he won. A year his passed since his graduation. In that year, Euathlus didn't take part in trials. Protagoras began to show impatience. He suggested that Euathlus pays his tuition fees. Euathlus refused. The Protagoras said, "If you won't pay the fee, I'll go to court. If the court rules that you have to pay as per the rule of the court. If the court rules "not to pay", then you'll win your first process and pay your tuition as per agreement". Since Euathlus had already mastered the art of arguing, he objected to Protagoras as such: You are wrong, my teacher. If the court rules "not to pay", I won't pay as per the rule of the court. If it rules "to pay", then I'll lose the process and won't pay as per agreement".

Who was right? Sometimes they say that both Protagoras and Euathlus were right. Such an answer to the question raised is reminiscent of a story of a village wise man.

"An elderly peasant came to the sage and asked "I argued with my neighbor". The peasant outlined the essence of the dispute and asked: "Who's right?"

The sage answered: "You're right"

After a while, the second of the disputants came to the sage. He also told about the dispute and asked: "Who's right?".

\section{The sage answered: "You're right"}

"How's that? - the wife asked the sage - That's right and the other's right?"

"And you're right as well, wife" - answered the sage"
Unintentional mistakes are made because of low culture of thinking, because of hastiness, and some other reasons. These are called paralogisms (from Greek paralogismos "wrong reasoning")

Abidance by the special logical rules allows avoiding mistakes in argumentations and critique. In accordance with three parts of argumentation and counter-argumentation, we'll divide this rules into three categories: in relation to thesis (A), in relation to arguments (B) and in relation to form (C). Some of these rules apply only to proof and refutation.

\section{SPECIAL LOGICAL RULES}

\section{A. Rules in relation to thesis, Possible Mistakes and Tricks}

1) First rule: It is necessary to analyze controversial ideas and explicitly formulate the thesis (in a form of a reasoning, system of reasoning, norm, system of norms, problem, hypothesis, concept etc.). This rule expresses the main condition for efficiency of argumentation and critique.

Abidance of this rule consists of implementing the following actions.

- First. In a statement (statements of the parties) it is necessary to single out the simplest components.

- Second action. It is necessary to establish the points of agreement and disagreement in the statements of the parties.

- Third action. Thesis (or theses) of the dispute should be agreed upon.

2) Second rule: Thesis must be formulated plain and clear.

- First, non-logical terms included in the wording of thesis shall be clarified. For this reason, we need to reformulate thesis.

Some may say that it is irrational to transport liquid in a hollow vessel with perforated bottom, while others object to this. This statement can be simplified as such: "It's irrational to carry liquid (for example, water) in a vessel with holes in its bottom, for example in a sieve". No one will object this statement.

Explicit definition is the best way of elaboration of descriptive terms. One of the encountered errors is when a definition of a term is given, but in the course of argumentation the phrase is used in another meaning.

- Secondly, it is necessary to identify the logical form of thesis, that is to identify or clarify logical terms.

3) Third rule: Thesis must not change in the process of argumentation and critique without special stipulations.

Infringement of this rule causes a mistake, called substitution of thesis. It is done in a case when one statement is put as a thesis, yet another statement similar to the first one is being reinforced or criticized, and in the end a conclusion on the initial statement is made. 
This mistake is made in the next argumentation.

Someone decided to prove that 3 times 2 equals not 6 but 4. In pursue of his strange ploy, he took a single match and asked those present to watch closely his train of thought.

If we snap the match in two, - declared the strange mathematician, - we'll have 2 the first time. If we do the same with one of the halves, we'll have 2 the second time. Finally, if we perform the same operation with the second half, we'll have 2 the third time. And so, if we take two three times, we'll get four, not six as it is commonly believed".

Instead of proving that " $3{ }^{\prime} 2=4^{\prime}$, instead it is proved that: "If we divide whole into two, and then we divide each half in two, we'll have four parts".

\section{B. Rules in Relation to Arguments, Possible Mistakes and Tricks}

1) First rule: Arguments must be formulated plain and simple.

Carrying out this rule requires:

- List all the arguments; in case if in the process of argumentation some arguments are discarded, the arguments are changed, the new ones are introduced, this must be stipulated; it's especially important to identify clearly unspoken arguments;

- Classify the arguments, that is group them together by their types. For example, while augmenting for advisability of purchasing the merchandise of a given company, to select a group of arguments that confirm the quality of the merchandise, a group of arguments that confirm the trendiness of the merchandise etc.

- Clarify descriptive terms, bind them to the concepts of expression or clarify the statements in some other way;

- Identify logical contains of arguments; clarify quantitative words, logical connections.

2) Second rule: Arguments must be justified (fully or partially).

In the context of proof and rebuttal this rule is formulated as such: arguments must be fully justified (proven logically or justified factually).

Infringement of the second rule, that demands that arguments must be justified, creates a mistake called "unjustified argument". There are several kinds of the mistake called "unjustified argument"

a) "False Argument": In this mistake, an argument made is an unjustified statement, that is also false. But the argumentator does not know about the falsehood of this statement.

This mistake is also made in case of the justification of statements about facts, final evaluation of which can only be made in the future. b) "Deceitful Argument": This (dubious in terms of semantics) name the logicians of the past gave to a mistake that is to bring statements, falsehood of which is known to the argumentator, as arguments. Making this mistake in most cases is a trick.

c) The third kind - "unjustified reference to authority": In argumentation it is possible to reference authorities (people, communities etc), but in this case it is necessary to carry out following conditions:

- Each authority is a specialist in a particular field; statements of an authority concerning said field can be referenced.

- References to authority are only probable arguments; they should be used only for confirmation of direct arguments;

- It is necessary to adduce not words pulled out of context, but thoughts, extracted as a result of an analysis of context.

If these conditions are not met, any thesis can be confirmed by quotations.

Described mistake turns into "deceitful argument", if the words adduced were not said by the authority, or if the authorities are made up. In latter case, the kind of mistake made is "unjustified reference to authority" that is called perjury.

d) "Circle in argumentation": The mistake is made this way. Thesis is justified by argument, yet one of the arguments is justified with said thesis. An example of a reasoning in which this mistake is made:

- $\quad$ Question. Did ancient hominids use tools?

Answer. We suppose that they did. Like chimpanzee, they had this potential ability, and they retained it when they left the forest.

- Question. But what did stimulate its development?

Answer. In an open area they needed tools to protect themselves from enemies.

- Question. Why?

Answer. Because their canines were small.

- Question. Why were their canines small?

Answer. Because they did not need large canines anymore. They were mastering uprightness, and this gave them more opportunities to use tools. Weapons allowed them to defend themselves more efficiently, and large canines lost their meaning as protection" [5]

3) Third rule: arguments must be relevant to the thesis.

Argument is relevant to the thesis of argumentation (counter-argumentation), if its acceptance, possibly in conjunction with other arguments, raises (lowers) the plausibility of the thesis. 


\section{Rules and mistakes in relation to form of argumentation and critique}

Let's formulate one general rule in relation to the form: relations between arguments and thesis must be, at the very least, the relations of confirmation.

Infringement of this rule causes a mistake in which "thesis is not confirmed". Applicable to a proof it is called "does not follow"

While arguing or researching for finished argumentation it's important to know, what is the logical connection between thesis and arguments: does the thesis necessarily follows the arguments; arguments just confirm the thesis; there is no logical connection between thesis and arguments. To solve this problem it is necessary to apply the teachings of logic about deductive and inductive reasoning. Herewith it should be noted that correctness or incorrectness of some methods of reasoning can be identified "by ear", without using pen and paper, but the analysis of other (complex reasonings) requires written applications of symbolic logic.

With time and complex practice in analysis of reasoning, logical culture will increase, and pencil will be used less and less often, and more and more correct and incorrect methods of reasoning will be distinguishable "by ear".

\section{CONCLUSION}

The logical-argumentative culture is an important part of educational culture. It is determined by the person's degree of proficiency of the means of argumentation and critique (ability to apply different methods and ways of argumentation and critique, technologies of realization of rules of argumentation and critique, knowledge of methods of opposing tricks), as well as degree of proficiency of the methods of logic (ability to apply such knowledge of logic as methods of reasoning, methods of clarifying statements, ability to react at logically and pragmatically incorrect questions and answers etc.). This article presents the most important of these means.

\section{REFERENCES}

[1] V. Yu. Ivlev, Theory and practice of argumentation. M.: Prospect 2009.

[2] M. B. Oseledchik, V.A.Inozemtsev, V.Yu.Ivlev, M.L.Ivleva. Logical-Philosophical Approach to the Interpretation of the Concept of Knowledge // Proceedings of the 2016 3rd International Conference on Education, Language, Art and Inter-cultural Communication (ICELAIC 2016). Advances in Social Science, Education and Humanities Research. Paris: Atlantis Press, 2017. Volume 40, pp. 297-301.

[3] V. Yu. Ivlev, V. A. Inozemtsev, M. B. Oseledchik, M. L. Ivleva. Categories of Modality and Their Use in Modern Biological Conceptions // Proceedings of the 2016 3rd International Conference on Education, Language, Art and Inter-cultural Communication (ICELAIC 2016). Advances in Social Science, Education and Humanities Research. Paris: Atlantis Press, 2017. Volume 40, pp. 687-691.

[4] V. Yu. Ivlev, N. D. Lepskaya, Modalities and logic // "Proceedings of the 2017 2nd International Conference on Contemporary Education, Social Sciences and Humanities". (ICCESSH 2017). Part of the series ASSEHR. Moscow, Russia. V.124, pp. 79-86.
[5] I. Maitland, Human genesis: Missing link. M., 1977. pp. 84-85. 